\title{
Regional modeling of rainfall-induced landslides using TRIGRS model by incorporating plant cover effects: case study in Hulu Kelang, Malaysia
}

\begin{abstract}
The objective of this paper is to develop a spatial temporal regional modeling of local rainfall patterns effect on the plant cover slopes in Hulu Kelang area. Rainfall interception, tree root cohesion, and tree surcharge were considered as main plant cover effects on the slope stability. In this regard, an improved version of the Transient Rainfall Infiltration and Gridbased Regional Slope stability model (TRIGRS) was performed using Microsoft Excel® and GIS framework system for coupled hydrologicalï mechanical modeling of rainfall-induced landslide by incorporating plant cover effects. The infiltration process of the improved model was integrated with the precipitation distribution method and rainfall interception approach while the slope stability analysis of TRIGRS model was replaced with the improved analysis with consideration of root cohesion and tree surcharge. In the following, the spatial temporal analysis of slope failures was performed using the monthly average rainfall during two different monsoon seasons of 2008 and 2009 for triggering shallow slope failure in Hulu Kelang area. The corresponding changes in pressure head and consequent water table depth were calculated during two monsoon seasons. Subsequently, factor of safety is computed using local rainfall patterns, along with root coefficient and tree surcharge in the study area. The results showed the plant-covered slopes are inducing an overestimation of the slope failure susceptibility using existing TRIGRS model, while the improved model resulted that less landslide susceptible areas were more representative of the actual stability conditions of the slopes at the study area.
\end{abstract}

Keyword: Rainfall interception; Rainfall-induced landslide; Root cohesion; Tree surcharge; TRIGRS 